\title{
Autocrine and paracrine stimulation of dopamine secretion by human neural stem cells: Role BDNF and GDNF
}

\author{
Ashok Chakraborty ${ }^{1 *}$ and Anil Diwan ${ }^{2}$ \\ ${ }^{1}$ Chief Scientist, Allexcel, Inc., 123 Wood Street, West Haven, CT 06484, USA \\ ${ }^{2}$ Chief Executive Officer, Allexcel, Inc., 123 Wood Street, West Haven, CT 06484, USA
}

\begin{abstract}
Background: Neural stem cells are multipotent cells which are capable of self-replication and differentiation into neurons, astrocytes or oligodendrocytes in the central nervous system. Therefore, one can expect that NSC transplantation can ultimately provide a better therapeutic approach in the treatment of neurodegeneration, like Parkinson's Disease (PD).
\end{abstract}

Aim: In order to use the therapeutic potential of neural stem cells, it is essential to fully understand the cellular and molecular mechanisms involved in the function of Dopamine secretion by the cells.

Methods: We assayed the growth potential and DOPAmine production of hNSCs in presence of neurotropic factors. Release of neurotropic factors by hNSCs also determined by ELISA.

Results: We found that hNSCs can secrete DOPAmine as well as some neurotropic factors, like Brain-Derived Neurotropic Factor (BDNF) and Glial cell-Derived Neurotropic Factors (GDNF). These factors can further supports the proliferation of hNSCS and DOPAmine production ability of the neural cells.

Conclusion: That way, an Autocrine-Paracrine regulatory system have been established in the neural cells.

\section{Introduction}

Parkinson's disease (PD) is characterized by the progressive loss of dopaminergic neurons in the substantia nigra pars compacta $(\mathrm{SNc})$ [1-3]. Specific neurotrophic factors that are secreted from neighboring cells, like GDNF, a glial cell line-derived neurotrophic factor [4], and BDNF, a brain-derived neurotrophic factor [5,6], are well known for their role in growth, survival, and differentiation of developing neurons [7-9]. These factors also have been found to attenuate the loss of nigrostriatal dopaminergic neurons in animal models of Parkinson's Disease (PD), and also interfere with both apoptotic and necrotic forms of cell death and promotes the survival of dopaminergic neurons in culture $[4,10]$.

Here we show that hNSCs can produce BDNF and GDNF along with DOPAmine, and those neurotropic factors can stimulate the proliferation of hNSCs in vitro, Further, these neurotropic factors can increase DOPAmine secretion by hNSCs. DOPAmine itself, can also induce the secretion of those neurotropic factors by neural cells, thereby established an autocrine-paracrine loop for dopaminergic function of hNSCs.

\section{Materials and methods}

1) Culture of hNSCs (Human Neural Stem Cells): hNSCs (H9) derived from adult normal human of female origin were purchased from ThermoFisher (Rockford, IL, USA). The growth and maintenance of undifferentiated hNSCs were conducted with human neural stem cell growth medium supplemented with human neural stem cell growth factors (GS2) and antibiotics (GS1) from Cell Applications (San Diego, CA, USA). In brief, hNSCs were cultured in 6-well tissue culture plates pre-coated with cell-matrix gel (ATCC, Manassas, VA) containing $5 \mathrm{ml}$ complete growth medium at $37^{\circ} \mathrm{C}$ in a $5 \% \mathrm{CO} 2$ humidified incubation chamber.

Sub-culturing and passaging of the hNSC spheres were done by Accutase, a cell dissociation reagent, (ATCC, Manassas, VA), into single cells. Single cells $\left(1 \AA \sim 10^{6}\right)$ were then plated in the 6-well tissues culture plates coated with Matrix gel (ATCC, Manassas, VA) in $4 \mathrm{ml}$ complete culture medium.

2) Proliferation assay by Cell-Glo Luminiscence reagent: Proliferation of cells was detected using the Cell-Titer-Glo Luminescent Cell Viability Assay kit (Promega, Madison, WI). For in vitro growth assays, cells ( $1 \times 10^{3} /$ well) were plated in $96-$ well plates and on the next day ' 0 day' reading followed by every alternate day cell growth was measured using the Cell-Titer-Glo-kit until for 6 days. Luminescence was read using the BioTek plate reader [11]. Results were expressed as percentage of vehicle-control cells. Results presented are Mean \pm SD from three separate experiments done in triplicate.

3) Detection of BDNF and GDNF protein concentration by ELISA: Enzyme-linked immunosorbent assays (ELISA) was performed to detect BDNF, and GDNF secreted by hNSCs in the culture supernatant at different days and in different groups. Standard curve was made with the preparations of standard compounds $(2000,1000,500,250,125$,

${ }^{\star}$ Correspondence to: Ashok Chakraborty, Chief Scientist, Allexcel, Inc., 123 Wood Street, West Haven, CT 06484, USA, E-mail: ashok.chakraborty@allexcel.com

Key words: BDNF, DOPAmine, dopaminergic neurons, GDNF, parkinson's disease Received: April 13, 2020; Accepted: April 20, 2020; Published: April 23, 2020 
$62.5,31.3$, and $0 \mathrm{pg} / \mathrm{mL}$ ) in each of $50 \mu \mathrm{L}$ volume. Standard solutions and test samples were added sequentially to the antibody pre-coated wells. Samples were thoroughly incubated at $37^{\circ} \mathrm{C}$ for 120 minutes. Wells were rinsed four times with wash buffer, and allowed to soak for 1 minute each time. The reaction plate was dried with filter paper. The biotinylated antibody working solution $(50 \mu \mathrm{L} /$ well $)$ was added and plates were incubated for 60 minutes at $37^{\circ} \mathrm{C}$. The wells were then washed four times with wash buffer. Enzyme-labeled antibody (rabbit anti-human NGF polyclonal antibody; BG, Shanghai, China) working solution $(50 \mu \mathrm{L} /$ well $)$ was added and incubated for 30 minutes at $37^{\circ} \mathrm{C}$. Wells were washed. Subsequently, 3,3', 5,5'-tetramethyl benzidine solution $(50 \mu \mathrm{L} /$ well $)$ was added for 15 minutes at $37^{\circ} \mathrm{C}$ in the dark. The reaction was terminated by the addition of 3,3',5,5'-tetramethyl benzidine stopping solution $(50 \mu \mathrm{L} /$ well $)$.

Absorbance values were measured at $450 \mathrm{~nm}$ with a microplate reader (Labsystems, Helsinki, Finland). The mean absorbance value for each standard sample was calculated. The mean value of the zero standard was subtracted from all absorbance values before result interpretation. The standard curve was generated by plotting the average absorbance value obtained for each of the eight standard concentrations on the vertical (Y) axis the corresponding concentration on the horizontal (X) axis. This standard curve was used to determine the concentration of the unknown sample.

4) DOPAmine level by ELISA: Dopamine release was quantified using ELISA kits (Eagle Bioscience, Nashua, NH; Cat\# DOP31-K01). All samples were stabilized immediately with orthophosphoric acid $(7.5 \%) /$ metabisulfate $(0.22 \mathrm{mg} / \mathrm{mL})$ and stored at $-80^{\circ} \mathrm{C}$ before analysis. Dopamine extraction, acylation, and enzyme immunoassay were performed according to the manufacturers' instructions. Every sample and standard was performed in duplicate. Absorbance was read using a microplate reader set to $450 \mathrm{~nm}$ and a reference wavelength set between 620 and $650 \mathrm{~nm}$. Data were from three independent experiments.

5) Protein determinations: Protein content was measured using the Bio-Rad Protein Assay Kit (Bio-Rad, Richmond, CA) with bovine serum albumin as the standard.

6) Cell counting: Cell count and viability measurements were done by staining the cells with Trypan Blue and then counting the number of viable cells with the Countess ${ }^{\mathrm{m}}$ automated cell counter (Invitrogen).

7) Statistical analysis: The t-test and one-way analysis of variance were used for statistically analyzing the data. All values are expressed as the mean \pm SD. P values $<0.05$ were considered significant. Results are representative of at least three experiments

\section{Results}

1) Production of BDNF or GDNF by hNSCs in culture (Table 1): The levels of BDNF or GDNF were assayed in the hNSC cell lysates by ELISA, and the values were expressed as ng/ $10^{5}$ Cells for BDNF, while GDNF was expressed as $\mathrm{pg} / 10^{5}$ Cells. The experimental data are Mean $\pm \mathrm{SD}$ from three separate experiments done in duplicate. $\mathrm{P}<0.05$.

Table 1. Secretion of BDNF and GDNF by hNSCs

\begin{tabular}{|c|c|}
\hline $\begin{array}{c}\text { BDNF } \\
\text { ng/10 } \text { Cells }\end{array}$ & $\begin{array}{c}\text { GDNF } \\
\mathrm{pg} / 10^{5} \text { Cells }\end{array}$ \\
\hline $0.43 \pm 0.10$ & $18.34 \pm 2.12$ \\
\hline
\end{tabular}

The levels of BDNF or GDNF were assayed in the hNSC cell lysates by ȨLISA. BDNF level was expressed as ng/10 Cells, while GDNF was expressed as pg/10 Cells. The experimental data are Mean \pm SD from three separate experiments. $\mathrm{P}<0.05$
2) Stimulation of BDNF and GDNF secretion by DA in hNSCs (Figure 1): The levels of BDNF or GDNF secretion in presence of DOPAmine (DA) in culture were measured in the hNSC cell lysates by ELISA. The level of BDNF was expressed as ng/ $10^{5}$ Cells, while GDNF was expressed as pg/ $10^{5}$ Cells. The experimental data are Mean \pm SD from three separate experiments done in duplicate. $\mathrm{P}<0.05$. It is obvious from the results that both the neurotropic factors (BDNF and GDNF) can stimulate at their physiological doses the DOPAmine production by hNSCs.

3) Auto-stimulation of BDNF and GDNF secretion in hNSCs (Figure 2): The levels of BDNF or GDNF, measured as above (Figure $1)$, were induced by BDNF and GDNF at their physiological doses $(0.5$ $\mu \mathrm{g} / \mathrm{mL}$ ). Effect of GDNF in this connection is much more higher than BDNF. Level of BDNF was expressed as ng $/ 10^{5}$ Cells, while GDNF was expressed as $\mathrm{pg} / 10^{5}$ Cells. The experimental data are Mean \pm SD from three separate experiments done in duplicate. $\mathrm{P}<0.05$.

4) Simulation of proliferation of hNSCs by BDNF and GDNF (Figure 3): Proliferation rate (as \%) of hNSCs were stimulated by BDNF and GDNF at their sublethal doses $(0.05 \mu \mathrm{g} / \mathrm{mL})$ in a time dependent manner. The experimental doses of the neurotropic factors were chosen from some preliminary experiments (not shown), and which is at par of the published data from elsewhere [12]. GDNF shows a little more efficacy over BDNF in stimulating the proliferation of hNSCs. The experimental results displayed here are from a representative experiments done in triplicate. Values are expressed as a Mean+ SD from triplicate data $(\mathrm{P}<0.05)$. This experiment was repeated three different times with similar results. The difference in values from experiment to experiment was less than $10 \%$.

5) BDNF and GDNF stimulates DOPAmine secretion by hNSCs (Figure 4): DOPAmine (DA) was measured by ELISA as described in our previous paper [13]. The production of DA was further induced by BDNF and GDNF treatment of the cells at their physiological doses $(0.05 \mu \mathrm{g} / \mathrm{mL})$. The experimental data were taken from a representative experiment done in triplicate. DA Values (ng/10 Cells) were expressed as a Mean $+\mathrm{SD}(\mathrm{P}<0.05)$. The difference in values from experiment to experiment was less than $10 \%$.

\section{Discussion}

Brain-derived neurotrophic factor (BDNF) and glial cell linederived neurotrophic factor (GDNF) are critical for the growth, survival, and differentiation of developing neurons [14].

These neurotrophic factors also play important roles in the survival and function of adult neurons, learning and memory, and synaptic plasticity [4]. The initial trophic characterization of GDNF was performed in midbrain dopaminergic neuronal cultures; and in this work, GDNF not only promoted DANs survival but also soma enlargement and neurite outgrowth [4].

GDNF promotes the expansion of dividing nestin-positive neural precursors and increases the neurosphere diameter; however, this latter increase may also be associated with an anti-apoptotic response, since $\mathrm{Bcl}-2$ expression is up-regulated and caspase- 3 expression is downregulated [15]. As shown in the study by Roussa and Krieglstein (2004) [16], GDNF does not increase TH expression in neurospheres derived from the ventral midbrain, but increases the expression of Nurr1 and Pitx3, the latter of which is a transcriptional factor that is part of the regulatory complex that maintains the dopaminergic phenotype. More recently, Nurr1 was reported to induce the expression of the co-receptor for GDNF, c-Ret. Nurr1-expressing cells exposed to 

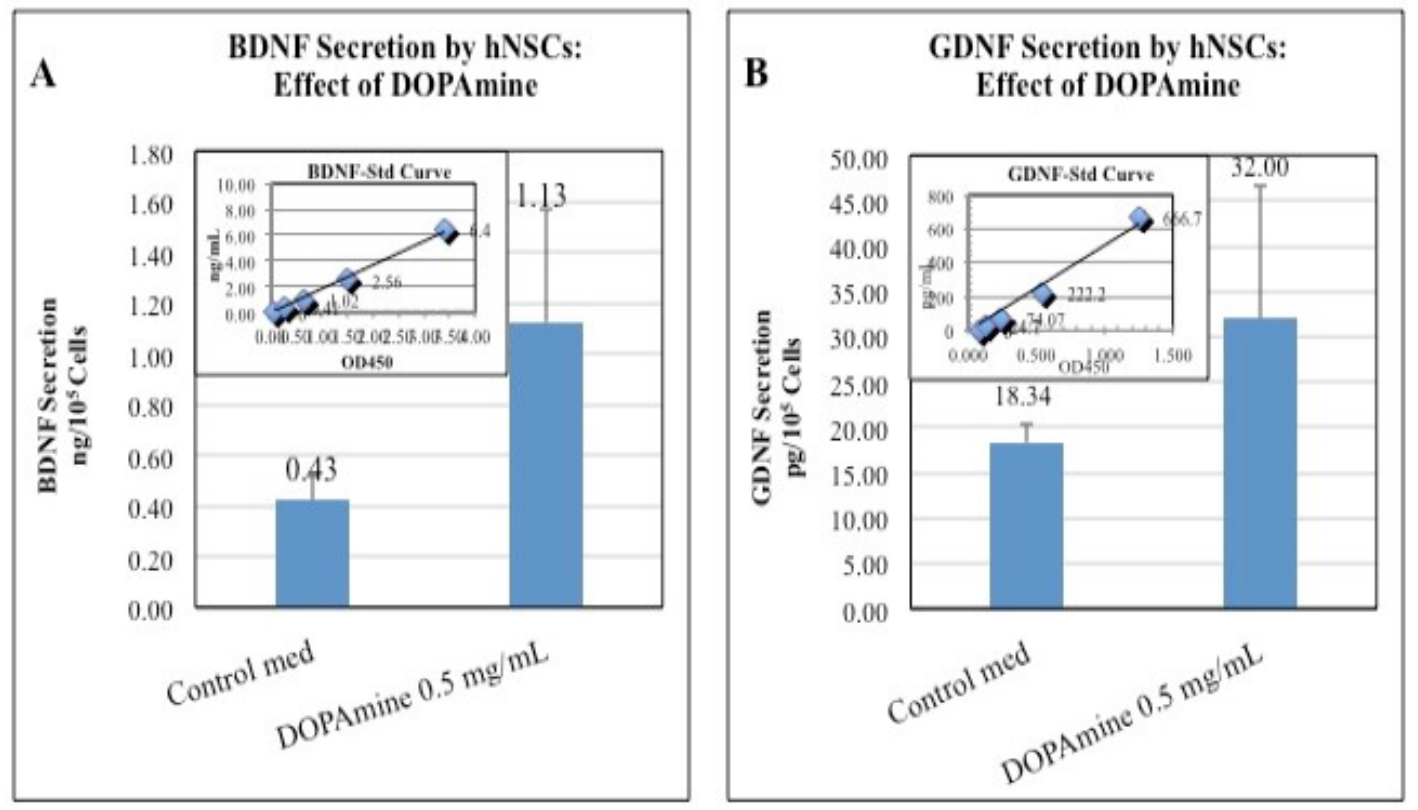

The levels of BDNF (Panel, A) and GDNF (Panel, B) secretion in presence of DOPAmine in culture were measured in the hNSC cell lysates by ELISA. BDNF level was expressed as ng/10 Cells, while GDNF was expressed as $\mathrm{pg} / 10^{5}$ Cells. The experimental data are Mean $\pm \mathrm{SD}$ from three separate experiments done in duplicate. $\mathrm{P}<0.05$. Inset is the Standard Curve of BDNF (Panel, A) and GDNF (Panel, B).

Figure 1. Stimulation of BDNF and GDNF Secretion by DA in hNSCs
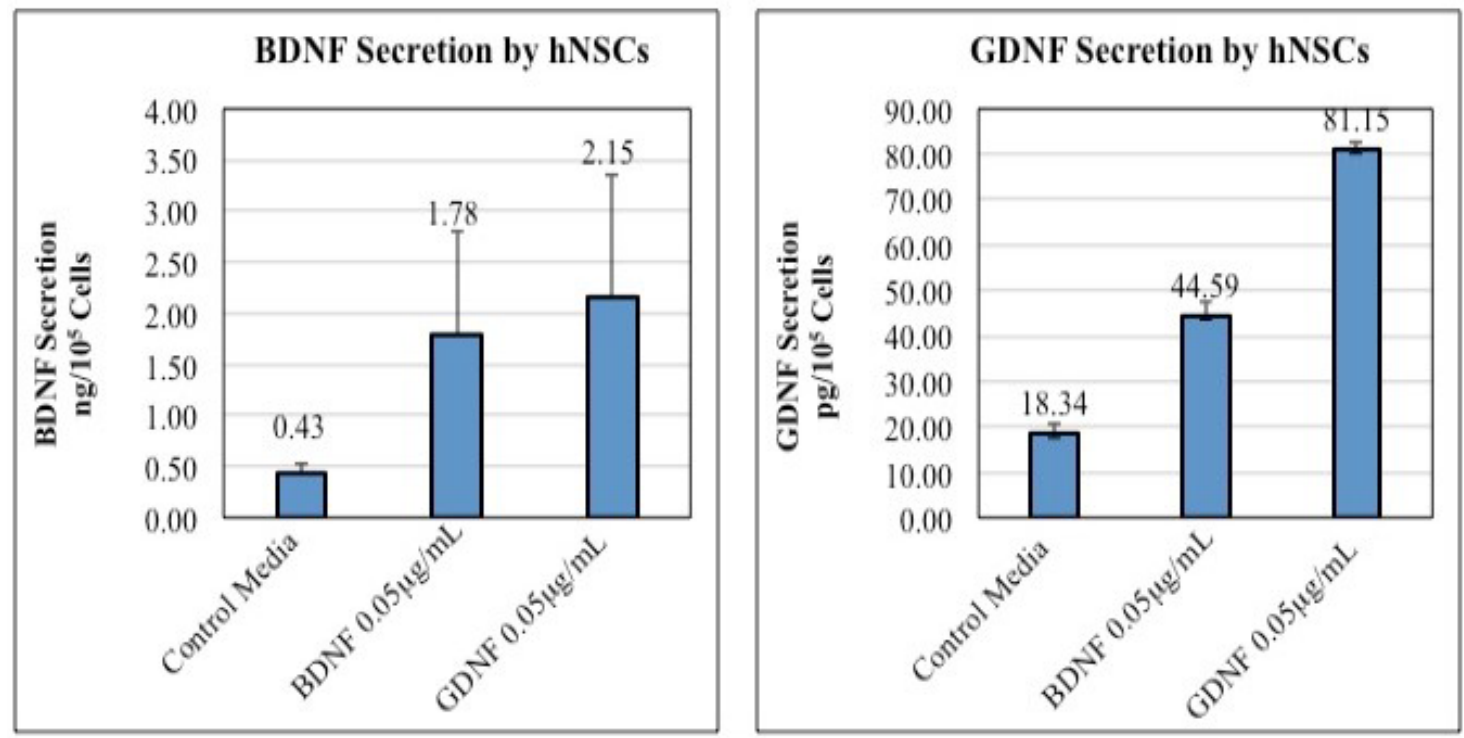

The levels of BDNF or GDNF were measured as above (Fig. 1) and found that their amounts were induced by BDNF and GDNF at their physiological doses $(0.5 \mathrm{mg} / \mathrm{mL})$. Effect of GDNF in this connection is much higher than BDNF. Level of BDNF was expressed as ng $/ 10^{5}$ Cells, while GDNF was expressed as pg/10 $/ 0^{5}$ Cells. The experimental data are Mean \pm SD from three separate experiments done in duplicate. $\mathrm{P}<0.05$.

Figure 2. Auto stimulation of BDNF and GDNF Secretion in hNSCs 


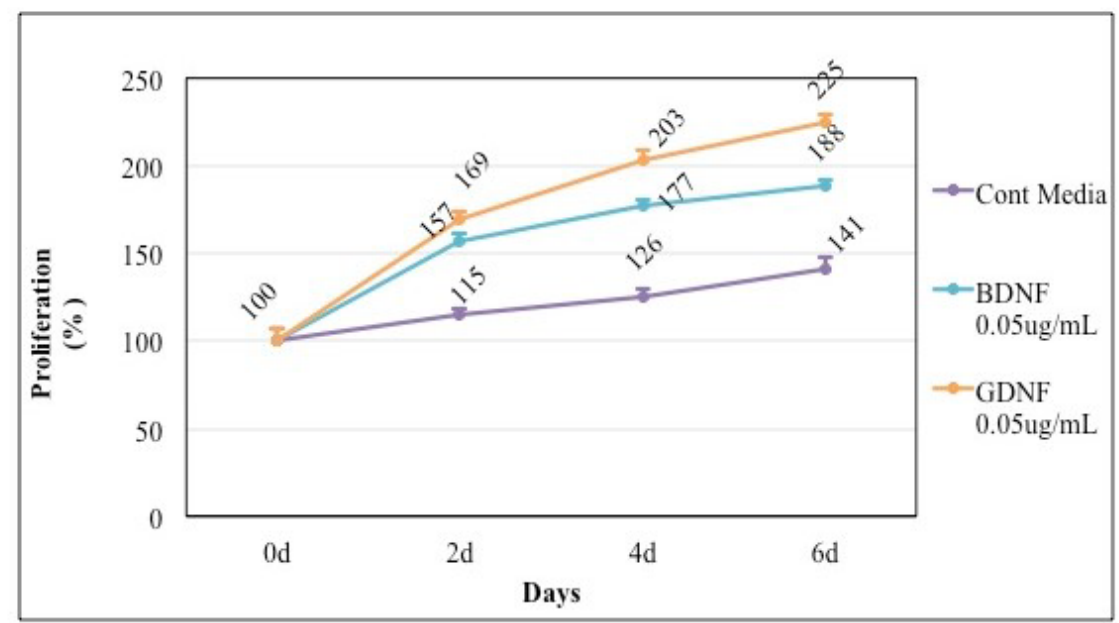

Proliferation rate (as \% of vehicle control) of hNSCs are stimulated by BDNF and GDNF at their sublethal doses $(0.05 \mu \mathrm{g} / \mathrm{mL})$ in a time dependent manner. The dose of the Neutropic factors was chosen from some preliminary experiments (not shown here), and which is at par of the published data from elsewhere ( ). GDNF shows a little more effective over BDNF in stimulating the proliferation of hNSCs. The experimental data were taken from a representative experiment done in triplicate. Values were expressed as a Mean $\pm \mathrm{SD}(\mathrm{P}<0.05)$. The difference in values from experiment to experiment was less than $10 \%$.

Figure 3. Simulation of Proliferation of hNSCs by BDNF and GDNF

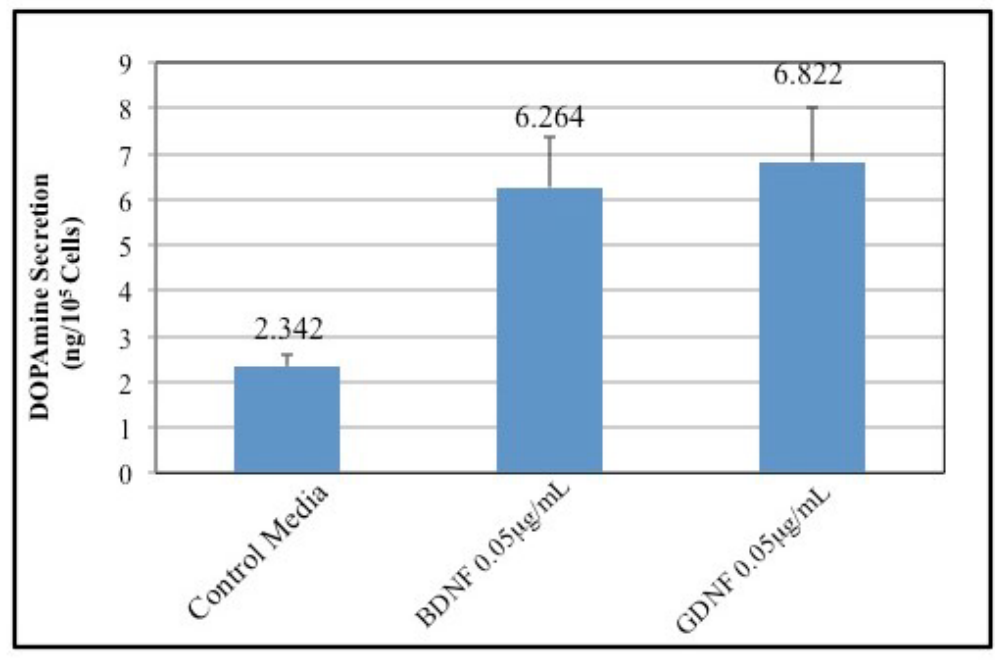

DOPAmine (DA) was measured by ELISA as described in our previous paper (Chakraborty and Diwan, In press). The production of DA was further induced by BDNF and GDNF treatment of the cells at their physiological doses $(0.05 \mathrm{mg} / \mathrm{mL})$. The experimental data were taken from a representative experiment done in triplicate. DA Values (ng/ $10^{5}$ Cells) were expressed as a Mean $\pm \mathrm{SD}(\mathrm{P}<0.05)$. The difference in values from experiment to experiment was less than $10 \%$.

Figure 4. Stimulation of DOPAmine Secretion by BDNF and GDNF

GDNF are eventually more responsive to GDNF, contributing to the up-regulation of Pitx3 expression and subsequently consolidating the dopaminergic phenotype [17]. In parallel, GDNF also increases DA transporter (DAT) activity [18]. Microarrays have corroborated that GDNF signaling favors the expression of genes associated with DA biosynthesis and recapture, as well as calcineurin. Inhibitors of ERK1/2 prevented these effects [19]. Thus, GDNF participates in proliferation and the acquisition of a dopaminergic phenotype. The mechanism by which GDNF interacts with other factors to promote this phenotype is still not clear.

Treatment of a human mesencephalic cell line with GDNF significantly increased dopaminergic differentiation and Dlk1 expression; practically all $\mathrm{TH}+$ neurons were positive for Dlk1 as well [20]. Thus, GDNF might direct the commitment of neurons towards specific phenotypes in addition to increasing neuronal survival. 
In neurons, the outgrowth of the dendritic tree occurs in parallel with electrophysiological maturation, which in turn facilitates DA release after potassium depolarization. A GDNF or BDNF treatment significantly increases DA release from ventral mesencephalic cultures [21]. GDNF enhances the quantal size of DA release in postnatal cultures [22]. Consistent with these findings, an injection of GDNF in the susbtantia nigra of adult rats increases DA release in vivo and promotes behavioral consequences such as an increase in spontaneous locomotor activity and higher velocity of movement [23]. Rolletschek, et al. (2001) showed that a cocktail including GDNF promotes the expression of the pro-dopaminergic gene Nurr1 in neural precursors [24]. Further, it was shown that Sertoli cells secrete GDNF, and GDNF-neutralizing antibodies block dopaminergic differentiation by $50 \%$ in them [25]. indicating that GDNF contributes in DOPAmine release. The addition of recombinant GDNF to differentiating human NPCs derived from ESCs promotes a higher level of dopaminergic differentiation after 21 days in culture.

GDNF signaling indisputably possesses potential therapeutic value for several pathologies, such as Parkinson's disease or amyotrophic lateral sclerosis, among other diseases, where it has been tested using molecular and cellular approaches [26-28]. The understanding of the entire range of properties of GDNF and other trophic molecules, like BDNF, could provide opportunities to investigate their broad actions and accelerate and/or improve therapies based on these factors.

In summary, the hNSCs utilized in this study exhibited an intrinsic ability to express neurotrophins. During development GDNF and BDNF, along with neurotrophin-3 (NT3), support the survival of sensory neurons through their cognate trk receptors [29-31]. The BDNF-responsive, trkB-containing population of sensory neurons is predominantly larger diameter and mechano sensitive [32]. although there is considerable overlap with the trkA population [33]. GDNF receptors are more wide- spread, with as many as $60 \%$ of dorsal root ganglion (DRG) neurons containing c-ret, while GFR components are found throughout the c-ret population, as well as in c- ret negative neurons $[34,35]$.

GDNF also plays a role in modulating nociceptive processing, but with contrasting in vitro and in vivo effects. In cultured DRG neurons, GDNF increases CAP sensitivity and TRPV1 expression [36,37]. and increases neuropeptide content [36]. Inflammation and nerve injury both increase BDNF content in DRG neurons and in the spinal cord, and this increase in BDNF is associated with the maintenance of a hyperalgesic state [38-41]. Furthermore, BDNF is released in the spinal cord upon noxious afferent stimulation $[42,43]$, and peripheral CAP application increases BDNF release at central terminals of sensory neurons [44]. Hence, BDNF might act as a neurotransmitter in the pain pathway in adult animals [45]. The trophic properties of BDNF on adult sensory neurons, particularly nociceptors, are poorly understood.

In brief, our present experimental result indicates that hNSCs produce BDNF and GDNF which can further stimulate its growth as well as DOPAmine release in an autocrine / paracrine manner. The understanding of the complete range of properties of this trophic molecule will allow us to investigate its broad mechanisms of action to accelerate and/or improve therapies for the neuro-pathological conditions, like Parkinson's Disease.

\section{Acknowledgement}

This research is supported by internal grant from AllExcel, Inc. Both the authors did contribute equally.

\section{Conflict of interest}

The authors report no conflicts of interest.

\section{References}

1. Taupin P, Gage FH (2002) Adult neurogenesis and neural stem cells of the central nervous system in mammals. J Neurosci Res 69: 745-749.

2. Alexander GE (2004) Biology of Parkinson's Disease: pathogenesis and pathophysiology of a multisystem neurodegenerative disorder. Dialogues Clin Neurosci 2004; 6: 259-280.

3. Zeng XS, Geng WS, Jia JJ, Chen L, Zhang PP (2018) Cellular and Molecular Basis of Neurodegeneration in Parkinson Disease. Front Aging Neurosci 10: 109.

4. Lin LF, Doherty DH, Lile JD, Bektesh S, Collins F (1993) GDNF: a glial cell linederived neurotrophic factor for midbrain dopaminergic neurons. Science 1260: 11301132.

5. Hyman C, Hofer M, Barde YA, Juhasz M, Yancopoulos GD, et al. (1991) BDNF is a neurotrophic factor for dopaminergic neurons of the substantia nigra. Nature 350: $230-232$

6. Klein RL, Lewis MH, Muzyczka N, Meyer EM (1999) Prevention of 6-hydroxydopamineinduced rotational behavior by BDNF somatic gene transfer. Brain Res 847: 314-320.

7. Bespalov MM, Saarma M (2007) GDNF family receptor complexes are emerging drug targets. Trends Pharmacol Sci 28: 68-74.

8. Chao MV (2003) Neurotrophins and their receptors: a convergence point for many signalling pathways. Nat Rev Neurosci 4: 299-309.

9. Chao MV, Rajagopal R, Lee FS (2006) Neurotrophin signalling in health and disease. Clin Sci (Lond) 110: 167-173.

10. Akerud P, Canals JM, Snyder EY, Arenas E (2001) Neuroprotection through delivery of glial cell line-derived neurotrophic factor by neural stem cells in a mouse model of Parkinson's disease. J Neurosci 21: 8108-8118.

11. Crouch SP, Kozlowski R, Slater KJ, Fletcher J (1993) The use of ATP bioluminescence as a measure of cell proliferation and cytotoxicity. J Immunol Methods 160: 81-88.

12. Erickson JT, Brosenitsch TA, Katz DM (2001) Brain-Derived Neurotrophic Factor and Glial Cell Line-Derived Neurotrophic Factor Are Required Simultaneously for Survival of Dopaminergic Primary Sensory Neurons In vivo. J Neurosci 21: 581-589.

13. Chakraborty A, Diwan A (2019) Selection of Cells for Parkinson's Disease CellTherapy. Int J Stem Cell Res Ther 6: 063.

14. Cai J, Hua F, Yuan L, Tang W, Lu J, et al. (2014) Potential therapeutic effects of neurotrophins for acute and chronic neurological diseases. BioMed Research International 2014: 601084

15. Lei Z, Jiang Y, Li T, Zhu J, Zeng S (2011) Signaling of glial cell line-derived neurotrophic factor and its receptor GFR $\alpha 1$ induce Nurr1 and Pitx 3 to promote survival of grafted midbrain-derived neural stem cells in a rat model of Parkinson disease. $J$ Neuropathol Exp Neurol 70: 736-747.

16. Roussa E, Krieglstein K (2004) Induction and specification of midbrain dopaminergic cells: focus on SHH, FGF8 and TGF-beta. Cell Tissue Res 318: 23-33.

17. Peng C, Aron L, Klein R, Li M, Wurst W, et al. (2011) Pitx3 is a critical mediator of GDNF-induced BDNF expression in nigrostriatal dopaminergic neurons. $J$ Neurosci 31: $12802-12815$.

18. Zhu S, Zhao C, Wu Y, Yang Q, Shao A, et al. (2015) Identification of a Vav2dependent mechanism for GDNF/Ret control of mesolimbic DAT trafficking. Nat Neurosci 18:1084-1093.

19. Consales C, Volpicelli F, Greco D, Leone L, Colucci-D'Amato L, et al. (2007) GDNF signaling in embryonic midbrain neurons in vitro. Brain Res 1159:28-39.

20. Christophersen NS, Grønborg M, Petersen TN, Fjord-Larsen L, Jørgensen JR, et al (2007) Midbrain expression of Delta-like 1 homologue is regulated by GDNF and is associated with dopaminergic differentiation. Exp Neurol 204: 791-801.

21. Feng L, Wang CY, Jiang H, Oho C, Mizuno K, et al. (1999) Differential effects of GDNF and BDNF on cultured ventral mesencephalic neurons. Mol Brain Res 66: 6270.

22. Pothos EN, Davila V, Sulzer D (1998) Presynaptic recording of quanta from midbrain dopamine neurons and modulation of the quantal size. J Neurosci 18: 4106-4118. 
23. Hebert MA, Van Horne CG, Hoffer BJ, Gerhardt GA (1996) Functional effects of GDNF in normal rat striatum: presynaptic studies using in vivo electrochemistry and microdialysis. J Pharmacol Exp Ther 279: 1181-1190.

24. Rolletschek A, Chang H, Guan K, Czyz J, Meyer M, et al. (2001) Differentiation of embryonic stem cell-derived dopaminergic neurons is enhanced by survival promoting factors. Mech Dev 105: 93-104.

25. Yue F, Cui L, Johkura K, Ogiwara N, Sasaki K (2006) Induction of midbrain dopaminergic neurons from primate embryonic stem cells by co-culture with Sertoli cells. Stem Cells 24: 1695-1706.

26. Richardson RM, Kells AP, Rosenbluth KH, Salegio EA, Fiandaca MS, et al. (2011) Interventional MRI-guided putaminal delivery of AAV2-GDNF for a planned clinical trial in Parkinson's disease. Mol Ther 19: 1048-1057.

27. Thomsen GM, Gowing G, Svendsen S, Svendsen CN (2014) The past, present and future of stem cell clinical trials for ALS. Exp Neurol 262: 127-137.

28. Rolan PE, O'Neill G, Versage E, Rana J, Tang Y, et al. (2015) First-in-human, doubleblind, placebo-controlled, randomized, dose-escalation study of BG00010, a glial cell line-derived neurotrophic factor family member, in subjects with unilateral sciatica. PLoS One 10: e0125034.

29. Lewin GR, Mendell LM (1994) Regulation of cutaneous C-fiber heat nociceptors by nerve growth factor in the developing rat. J Neurophysiol 71: 941-949.

30. Molliver DC, Wright DE, Leitner ML, Parsadanian AS, Doster K, et al. (1997) IB4binding DRG neurons switch from NGF to GDNF dependence in early postnatal life. Neuron 19: 849-861.

31. Liebl DJ, Klesse LJ, Tessarollo L, Wohlman T, Parada LF (2000) Loss of brain-derived neurotrophic factor-dependent neural crest- derived sensory neurons in neurotrophin-4 mutant mice. Proc Natl Acad Sci USA 97: 2297-2302.

32. Lindsay RM (1996) Role of neurotrophins and trk receptors in the development and maintenance of sensory neurons: an overview. Philos Trans $R$ Soc Lond B Biol Sci 351: $365-373$

33. McMahon SB, Armanini MP, Ling LH, Phillips HS (1994) Expression and coexpression of Trk receptors in subpopulations of adult pri- mary sensory neurons projecting to identified peripheral targets. Neuron 12: 1161-1171.

34. Kashiba H, Uchida Y, Senba E (2003) Distribution and co-localization of NGF and GDNF family ligand receptor mRNAs in dorsal root and nodose ganglion neurons of adult rats. Brain Res Mol Brain Res 110: 52-62.
35. Honda T, Takahashi M, Sugiura Y (1999) Co-localization of the glial cell line derived neurotrophic factor and its functional receptor c-RET in a subpopulation of rat dorsal root ganglion neurons. Neurosci Lett 275: 45-48.

36. Ogun-Muyiwa P, Helliwell R, McIntyre P, Winter J (1999) Glial cell line derived neurotrophic factor (GDNF) regulates VR1 and sub- stance $\mathrm{P}$ in cultured sensory neurons. Neuroreport 10: 2107-2111.

37. Bron R, Klesse LJ, Shah K, Parada LF, Winter J (2003) Activation of Ras is necessary and sufficient for upregulation of vanilloid receptor type 1 in sensory neurons by neurotrophic factors. Mol Cell Neurosci 22: 118-132.

38. Cho HJ, Kim SY, Park MJ, Kim DS, Kim JK, et al. (1997) Expression of mRNA for brainderived neurotrophic factor in the dorsal root ganglion following peripheral inflammation. Brain Res 749: 358-362.

39. Cho HJ, Kim JK, Zhou XF, Rush RA (1997) Increased brain-derived neurotrophic factor immunoreactivity in rat dorsal root ganglia and spinal cord following peripheral inflammation. Brain Res 764: 269-272.

40. Tonra JR, Curtis R, Wong V, Cliffer KD, Park JS, et al. (1998) Axotomy upregulates the anterograde transport and expression of brain-derived neurotrophic factor by sensory neurons. $J$ Neurosci 18: 4374-4383.

41. Ha SO, Kim JK, Hong HS, Kim DS, Cho HJ (2001) Expression of brain- derived neurotrophic factor in rat dorsal root ganglia, spinal cord and gracile nuclei in experimental models of neuropathic pain. Neuroscience 107: 301-309.

42. Kerr BJ, Bradbury EJ, Bennett DL, Trivedi PM, Dassan P, et al. (1999) Brainderived neurotrophic factor modulates nociceptive sensory inputs and NMDA-evoked responses in the rat spinal cord. J Neurosci 19: 5138-5148.

43. Pezet S, Malcangio M, Lever IJ, Perkinton MS, Thompson SW, et al. (2002) Noxious stimulation induces Trk receptor and downstream ERK phosphorylation in spinal dorsal horn. Mol Cell Neurosci 21: 684-695.

44. Lever IJ, Bradbury EJ, Cunningham JR, Adelson DW, Jones MG, et al. (2001) Brainderived neurotrophic factor is released in the dorsal horn by distinctive patterns of afferent fiber stimulation. J Neurosci 21: 4469-4477.

45. Thompson SW, Bennett DL, Kerr BJ, Bradbury EJ, McMahon SB (1999) Brainderived neurotrophic factor is an endogenous modulator of nociceptive responses in the spinal cord. Proc Natl Acad Sci USA 96: 7714-7718.

Copyright: $\bigcirc 2020$ Chakraborty A. This is an open-access article distributed under the terms of the Creative Commons Attribution License, which permits unrestricted use, distribution, and reproduction in any medium, provided the original author and source are credited. 